\title{
GPPS-BJ-2019-0090
}

\section{EXPERIMENTAL INVESTIGATIONS OF EFFECTS OF VENTURI ANGLE ON THE SPRAY STRUCTURE}

\author{
Xiongjie Fan \\ 1. University of Chinese Academy of \\ Sciences, \\ 2. Key Laboratory of Light-duty Gas-turbine, \\ Institute of Engineering Thermophysics \\ fanxiongjie@iet.cn \\ Beijing, China \\ Yulan Wang \\ 1. University of Chinese Academy of \\ Sciences, \\ 2. Key Laboratory of Light-duty Gas-turbine, \\ Institute of Engineering Thermophysics \\ wangyulan@iet.cn \\ Beijing, China \\ Qingbei Qiao \\ 1. University of Chinese Academy of \\ Sciences, \\ 2. Key Laboratory of Light-duty Gas-turbine, \\ Institute of Engineering Thermophysics \\ qiaoqingbei@iet.cn \\ Beijing, China
}

\begin{abstract}
In this paper, the spray characteristics of a double-swirl low-emission combustor are analysed by using PIV and PLIF technologies in an optical three-sector combustor test rig. The interactions between sectors and the influence of venturi angle on spray structure are explained. The results illustrate that the flow field plays a decisive role in the forming of spray structure. The interactions between sectors make the differences of flow field and spray structure between sectors. The venturi angle has a great influence on the spray structure and interactions between sectors. In a word, the results of the mechanism of spray organization in this study can be used to support the design of new low-emission combustor.
\end{abstract}

\section{INTRODUCTION}

There is an urgent need of improving combustion efficiency and decreasing emission pollution with the increase of stringent regulations on pollutant emissions [1, 2]. Nowadays, in order to improve the fuel atomization performance and reduce pollution, fuel-staged partially premixed combustors are applied. The combustor consists of pilot stage and main stage. The pilot stage adopts diffusion

\author{
Cunxi Liu \\ 1. University of Chinese Academy of \\ Sciences, \\ 2. Key Laboratory of Light-duty Gas-turbine, \\ Institute of Engineering Thermophysics \\ liucunxi@iet.cn \\ Beijing, China \\ Kaixing Wang

\section{University of Chinese Academy of Sciences,} \\ 2. Key Laboratory of Light-duty Gas-turbine, \\ Institute of Engineering Thermophysics \\ wangkaixing@iet.cn \\ Beijing, China
}

\section{Gang Xu \\ 1. University of Chinese Academy of Sciences, \\ 2. Key Laboratory of Light-duty Gas-turbine, Institute of Engineering Thermophysics \\ Premix1@126.com \\ Beijing, China}

combustion to improve the ignition and the main stage adopts partially premixed combustion to improve combustion efficiency, avoid hot streak and reduce pollution emission. Air-blast nozzle is commonly used in low-emission combustor, in which the flow field organization and the spray organization determine the combustion efficiency and temperature distribution.

Innovative designs for coping with operability and future regulations on pollution emissions has been done by a lot of researchers. Swirl cup combustors basing on swirl-stabilized combustion have been applied extensively to modern aero engine combustors because of the excellent combustion performance[3]. Hence, many researchers have carried out a lot of studies on the flow field, spray and combustion performance of swirl cup combustors. Wang et al., Fu et al., and Colby et al. studied the effects of geometry parameters on the flow field and spray, including flare geometry, confinement, and swirl angle et [4-7]. Ateshkadi et al.[8] studied the effect of swirl vane angle, swirl sense and venturi on LBO performance, and a new LBO correlation model accounting for heterogeneous reaction and geometry of mixer component is developed. Ateshkadi[5] and Mongia[9] 
studied the downstream spray field of a swirl cup combustor using PLIF technology, the results showed that venturi can control the area of fuel distribution, and form a typical cone distribution. Hadef[10] researched the effect of co- and counter-swirl on the droplet characteristics. The results indicated that the atomization was finer and more spatially dispersed in the counter-swirl configuration. This advantage leads to easier ignition, a wider burning range, and lower pollutant emissions, which help to improve combustion efficiency. Based on these studies, the spray structure, the flow field structure, the interactions between swirling air streams, the main factors determining the spray and regularity have been given for the swirl cup combustor.

Recently, a lot of researches on the flow field and spray performance of the fuel-staged low-emission combustor have been carried out. Li et al. [11] used the PIV technology to measure the flow field of a three-swirl combustor under cold condition, and studied how the air amount, the swirler structure and the length of the mixing tube influence the flow field. Woo[12] studied the influence of the blade rotation direction on the flow field and spray field of a double-radialswirl combustor. Lilley et al. [13] summarized the recirculation characteristics of cold flow and hot flow, and found that combustion have a major impact on the flow field. Elkady, Li, Cai et al. from Cincinnati [14-16] conducted a series of optical measurements and numerical simulations on multi-stage swirler, and studied how the swirl number influence the flow field and spray field. Yuan Yixiang, Lin Yuzhen, Liu Wei et al. [17-19]studied the influence of swirler rotation and step height on the flow field and spray field of fuel-stage combustor. Zhang Chi [20] studied the SMD and $\mathrm{N}$ of a counter swirler, the results showed that with the increase of pressure drop, the SMD and the N gradually decreased, and the fuel distribution become less uniform. Liu Cunxi et al.[21] used the PIV and PLIF technology to study the flow field and spray field of a three-swirl combustor under non-reacting conditions, and studied how the venturi angle and main swirl angle influence the flow field and spray field. The results show that the recirculating air streams in main stage will affect the trajectory of pilot air steams and location of vortex in pilot recirculation zone, and the main swirl angle has a great impact on droplet spatial distribution. Under the same overall pressure loss, the spray cone angle increases with venturi angle. The above researches are mainly based on single-sector combustor, the flow field and spray organization process and structure of single-sector combustor have been basically explained. However, for the fuel-staged low-emission combustor, more than $60 \%$ of the total combustor air goes through the sector, which induces the enhanced interactions between sectors, the flow field and spray characteristics are also affected by the interactions between sectors[22], but now the interaction process is still unclear.

In this paper, a three-sector optical visible combustor is designed for a type of double-swirl low-emission combustor (BUAA TeLESS). There are three different venturi models with different venturi angles (PC28: $28^{\circ}$, PB52: 52 ${ }^{\circ}$, PB90: $90^{\circ}$ ). In order to study the effects of venturi angle on the spray structures and the interactions between sectors, the experimental investigations of the spray structures at various testing Planes in the low-emission combustors with different venturi angles $\left(28^{\circ}, 52^{\circ}, 90^{\circ}\right)$ have been carried out.

\section{EXPERIMENTAL SETUP}

\section{Model Combustor}

The optical three-sector combustor test rig is shown in Figure 1. The combustor has two-stage reverse swirlers (Figure 1(a)). The pilot stage uses a pressure-swirl atomizer for primary atomization, and the pilot stage blades are counter clockwise, the main stage blades are clockwise. The pilot stage is in a swirl cup structure, there are three different venturi models with different venturi angles (PC28: $28^{\circ}$, PB52: $\left.52^{\circ}, \mathrm{PB} 90: 90^{\circ}\right)$. The pressure difference $(\Delta \mathrm{P})$ is measured between the front of the swirler and the behind of the swirler, and the relative swirler pressure drop is defined as $\Delta \mathrm{P} / \mathrm{P} 3$. Quartz glass measurement windows are arranged on the upper side and the right side of the test rig.

Figure 1(b) shows the measurement Planes ( Plane 1 Plane 5 ), the distance between Plane 1 to Plane 5 is $107 \mathrm{~mm}$, the test Plane is $160 \mathrm{~mm} X 140 \mathrm{~mm}$. Plane 1 is the central Plane of the middle sector, Plane 5 is the central Plane of the side sector, and all Planes are uniform distribution. In the test rig, the $\mathrm{X}$ axis is axial direction, the $\mathrm{Y}$ axis is radial direction.

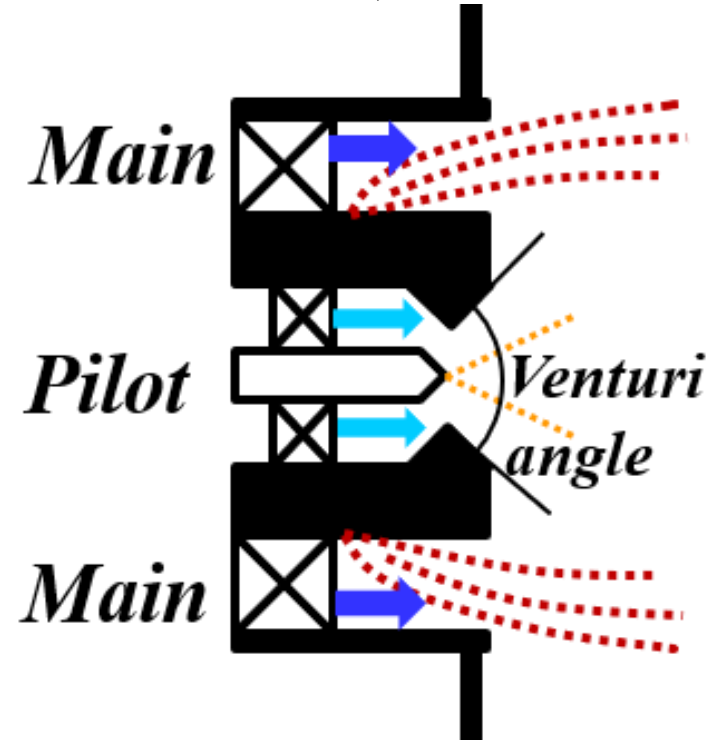

Figure 1(a). Swirler structure 


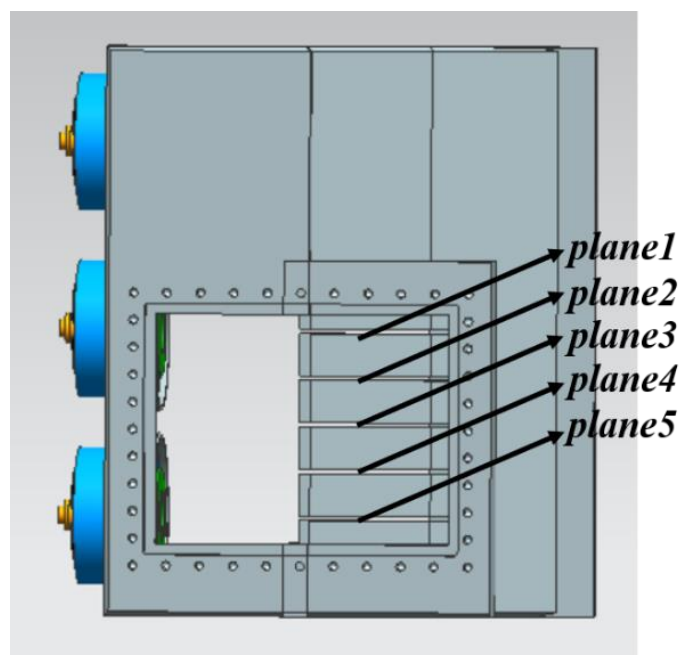

Figure 1(b). Experimental model

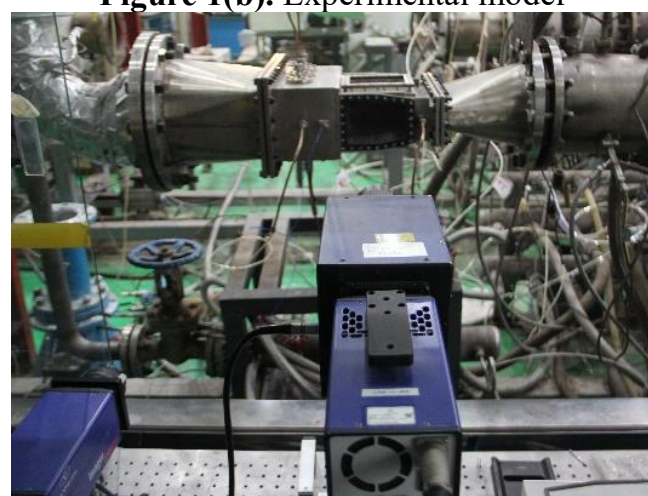

Figure 1(c). Combustor test rig

\section{Optical Setup}

The experiment was carried out on the spray/combustion optical diagnostic test bench of the Institute of Engineering Thermophysics, Chinese Academy of Sciences. Under normal temperature and pressure condition, swirler pressure drop $\Delta \mathrm{P} / \mathrm{P} 3$ of $1 \%, 2 \%, 3 \%, 4 \%$ and fuel-air ratio of 0.02 were selected in this study for the underground ignition condition.

The optical setup is shown in Figure 2, which combines an image capture, a laser system, and a controlling system.

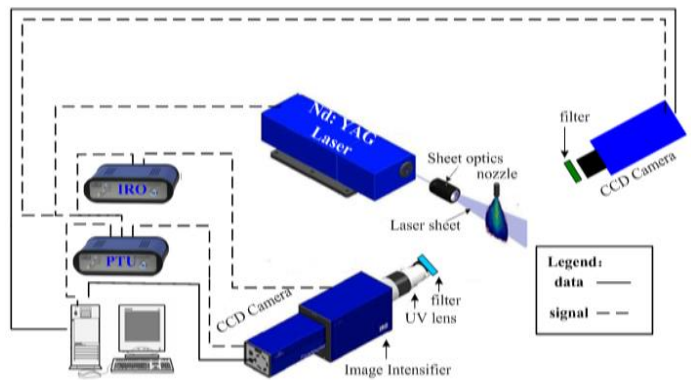

Figure 2. Optical setup

RP-3 kerosene is used for spray and combustion experiments, and $\mathrm{TiO} 2$ particles for PIV measurements. There are no fuel droplets in the PIV experiments. The detail of the equipment we use is the same with that in paper [21].

\section{RESULTS AND DISCUSSION}

The influence of venturi angle on the spray characteristics of Plane 1 and Plane 5
Figure 3 and Figure 4 show the flow field and spray characteristics of Plane 1 and Plane 5 under the pressure drop of $3 \%$ and fuel-air ratio of 0.02 , the venturi angles are $28^{\circ}$, $52^{\circ}, 90^{\circ}$.

It can be seen that the flow field mainly contains a highspeed jet with an expansion angle at the exit of the main stage swirler and a big recirculation zone with two vortices in the central area. Comparing the flow field structure and the spray structure, it is found that the flow field plays a decisive role in the forming of spray structure. The spray cone is mainly formed by the high-speed jet as the droplets are following the swirl air, and the recirculation zone has a great influence on the fuel distribution in the central area.

From Figure 3, It can be seen that there are some differences between the spray structure of middle sector and side sector under the same pressure drop and fuel-air ratio, which are mainly induced by the interactions between sectors (as shown in Figure 5). For example: the fuel concentration in the central area of Plane 5 is higher than that of Plane 1, and there is no hollow spray cone in Plane 5, especially when the venturi angle is $52^{\circ}, 90^{\circ}$. The main reason is that the width of the recirculation zone, the jet velocity and the jet expansion angle in Plane 5 are higher than those in Plane 1 (as shown in Figure 4 and Figure 6). The flow field in middle sector is affected by the swirling flow of two side sectors, which makes the swirl intensity attenuate greatly, and affects the development of the swirl flow in the radial direction, resulting in a small expansion angle of the flow field and a small width of the recirculation zone. The attenuation of side sector swirl intensity is smaller than the middle sector, which results in a higher expansion angle and width of the recirculation zone. The large swirl intensity of side sector induces that part of the fuel in the middle sector is drawn to the side sector so that the fuel concentration in the central area of Plane 5 is higher than that of Plane 1. The higher expansion angle and width of the recirculation zone of side sector induce that more fuel following the swirl air into the recirculation zone, and the fuel distribution be more uniform, the hollow spray cone disappear.

In addition, it can be found that the venturi angle has a great influence on the flow field and spray structure. There are larger fuels at upstream of Plane 1 as the venturi angle becomes higher, especially when the venturi angle is $90^{\circ}$. As the venturi angle becomes higher, there is bigger area inside the pilot stage, which may induce that more fuel droplets following the pilot swirl air directly into the main combustion zone, and less fuel droplets impact the venturi wall to form a film. From Figure 3, we can also see that the spray cone when the venturi angle is $52^{\circ}$ is smaller than that when the venturi angle is $28^{\circ}$ or $90^{\circ}$. The main reason may be that when the venturi angle is $28^{\circ}$, there is a relatively short length of the venturi wall, the velocity loss of fuel is small and the swirl intensity is big enough to induce a large radial velocity, so that the fuel will has a large spray cone. When the venturi angle is $90^{\circ}$, the exit of the venturi is relatively big, and the angle of fuel film is big enough to make a large spray cone. 


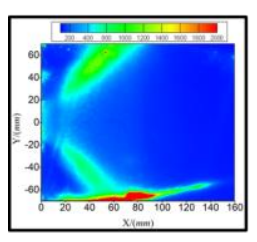

PC28-plane1

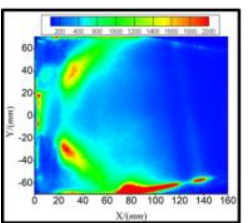

PC28-plane5

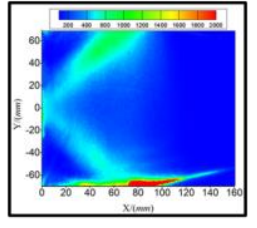

PB52-plane1

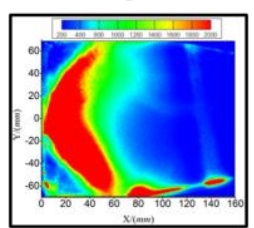

PB52-plane5

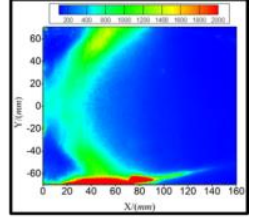

PB90-plane1

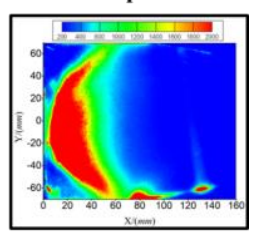

PB90-plane5
Figure 3. Spray characteristics of Plane 1 and Plane 5 under the pressure drop of $3 \%$ and fuel-air ratio of 0.02

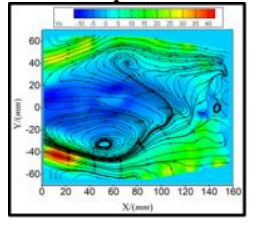

PC28-plane1

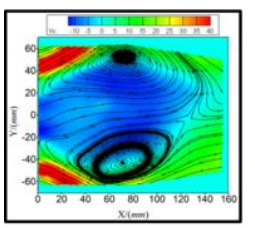

PC28-plane5

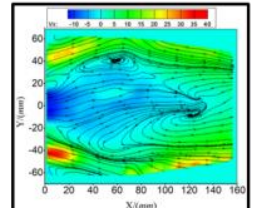

PB52-plane1

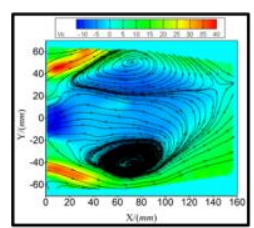

PB52-plane5

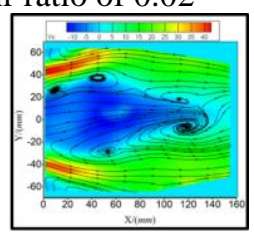

PB90-plane1

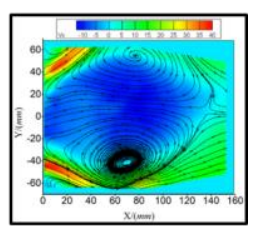

PB90-plane5
Figure 4. Flow field characteristics of Plane 1 and Plane 5 under the pressure drop of $3 \%$

Side sector Middle sector Side sector

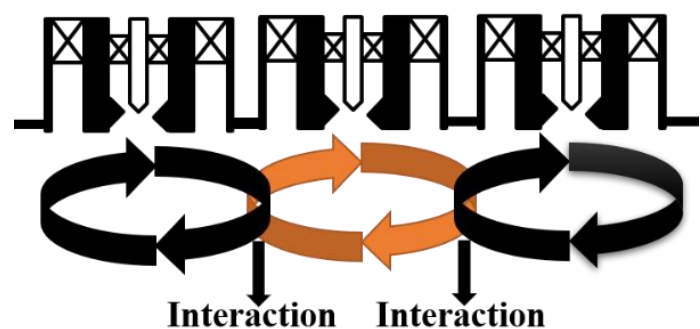

Figure 5. Interactions between sectors

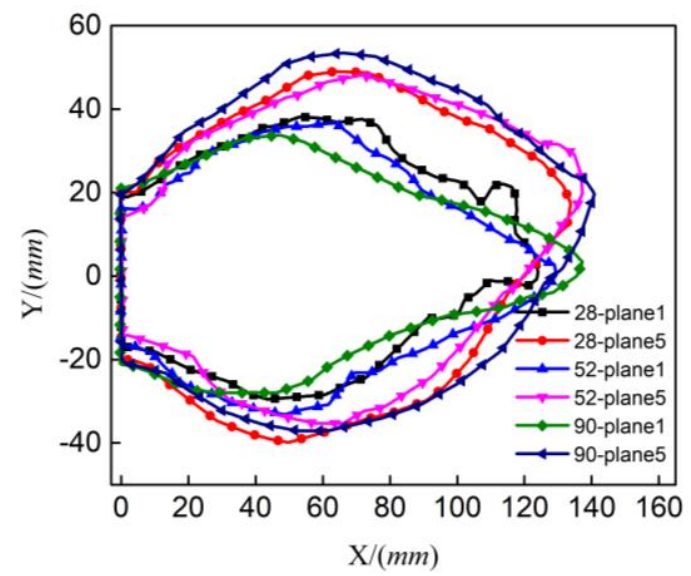

Figure 6. Comparison of the recirculation zone of Plane 1 and Plane 5 under the pressure drop of $3 \%$
Figure 7 shows the radial distribution of fuel at different axial positions when the venturi angle is $28^{\circ}$. It can be seen that the fuel distribution intensity at an axial position of $30 \mathrm{~mm}$ from the exit of swirler is higher than that of $40 \mathrm{~mm}$ and $50 \mathrm{~mm}$, and with the increase of axial position, the radial position at where the fuel distribution intensity reaches the maximum becomes higher, but the maximum fuel distribution intensity becomes smaller. The main reason is that the peak concentration drops with the increase of the axial coordinate due to the cone spreading.

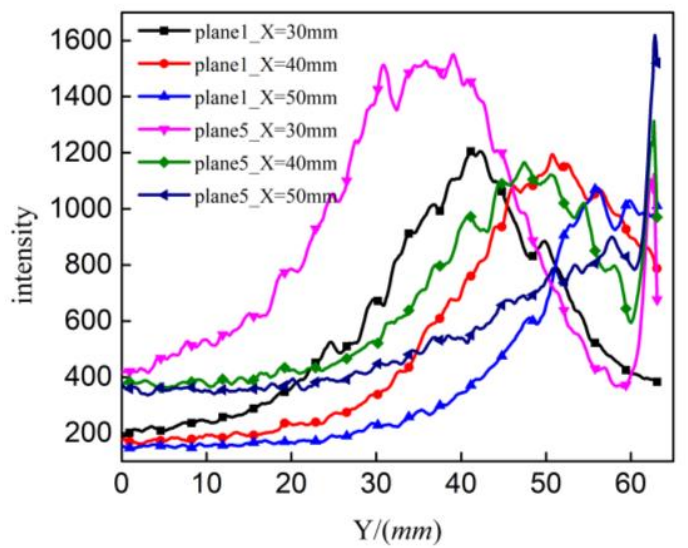

Figure 7. The radial distribution of fuel at different axial positions when the venturi angle is $28^{\circ}$

The influence of venturi angle on the spray characteristics of Plane 3

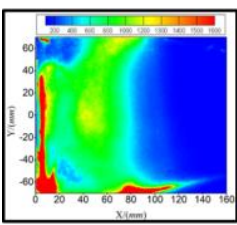

PC28-plane3

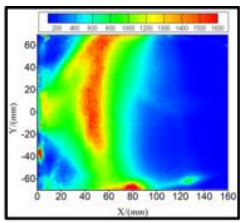

PB52-plane3

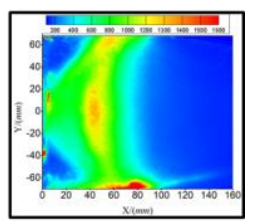

PB90-plane3
Figure 8. Spray characteristics of Plane 3 under the pressure drop of $3 \%$ and fuel-air ratio of 0.02

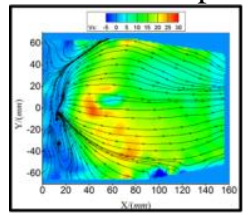

PC28-plane3

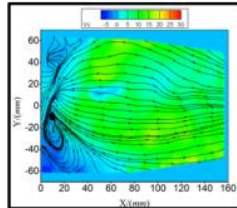

PB52-plane3

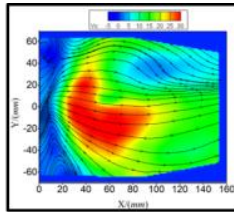

PB90-plane3
Figure 9. Flow field characteristics of Plane 3 under the pressure drop of $3 \%$

Figure 8 and Figure 9 shows the flow fields and spray structures of different venturi angles of Plane 3 under pressure drop of $3 \%$ and fuel-air ratio of 0.02 .

Figure 8 and Figure 3 shows that the fuel distribution area of Plane 3 is bigger than that of Plane 1 and Plane 5, and more uniform. The fuel distribution is influenced by the flow field and the interactions between sectors. It can be seen from Figure 9 that the velocity of Plane 3 is small, especially the radial velocity, which is induced by the interactions between the flow fields of sectors. The interactions between the flow fields make the swirl intensity attenuate greatly, and affect the development of the swirl in the direction of radial. 
In addition, the results show that there is a recirculation zone at upstream of Plane 3 when the venturi angle is $28^{\circ}$ and $52^{\circ}$, whereas not one when the venturi angle is $90^{\circ}$. When the venturi angle is $90^{\circ}$, there is a low-velocity zone at the upstream. We can also see that the fuel account at upstream of Plane 3 when the venturi angle is $28^{\circ}$ is the largest, and that of $90^{\circ}$ is the smallest, which may be induced by the flow field (recirculation zone and low-velocity zone) at upstream of Plane 3. The recirculation zone and the lowvelocity zone are harmful to the swirler, which may cause the carbon deposit.

The influence of pressure drops on the spray characteristics of Plane 1 (Model: PC28)

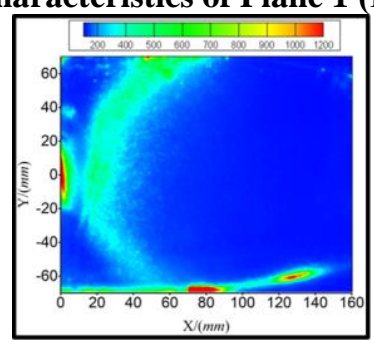

$\Delta P / P_{3}=1 \%$

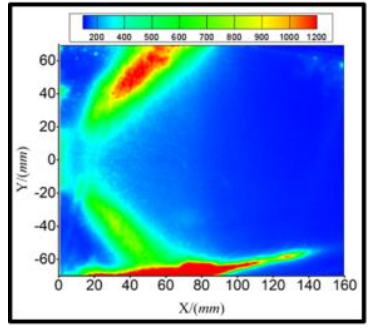

$\triangle P / P_{3}=3 \%$

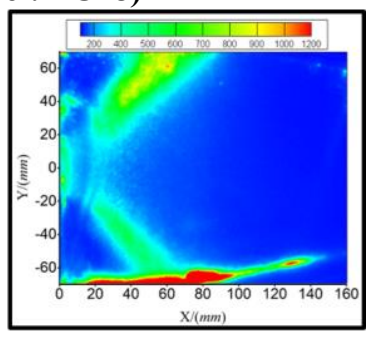

$\Delta P / P_{3}=2 \%$

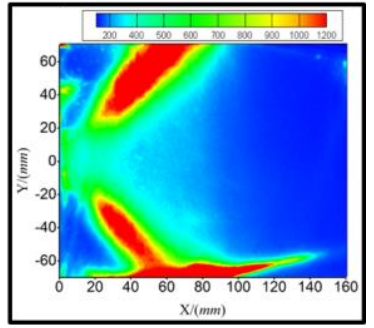

$\triangle P / P_{3}=4 \%$
Figure 10. Spray characteristics of Plane 1 under different pressure drops when the fuel-air ratio is 0.02

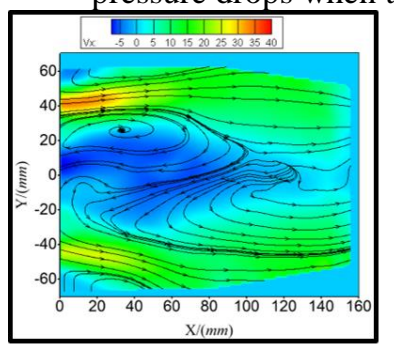

$\triangle P / P_{3}=1 \%$

$\Delta P / P_{3}=3 \%$

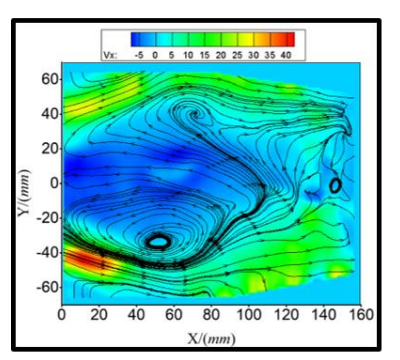

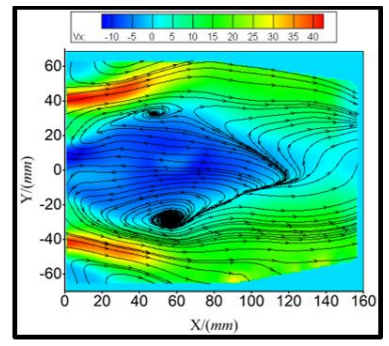

$\Delta P / P_{3}=2 \%$

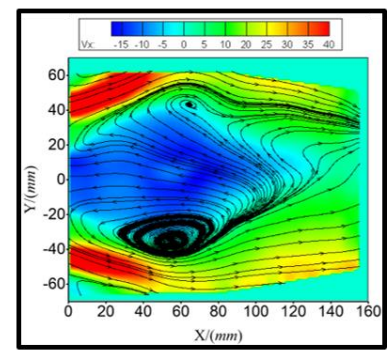

$\triangle P / P_{3}=4 \%$
Figure 11. Flow field characteristics of Plane 1 under different pressure drops

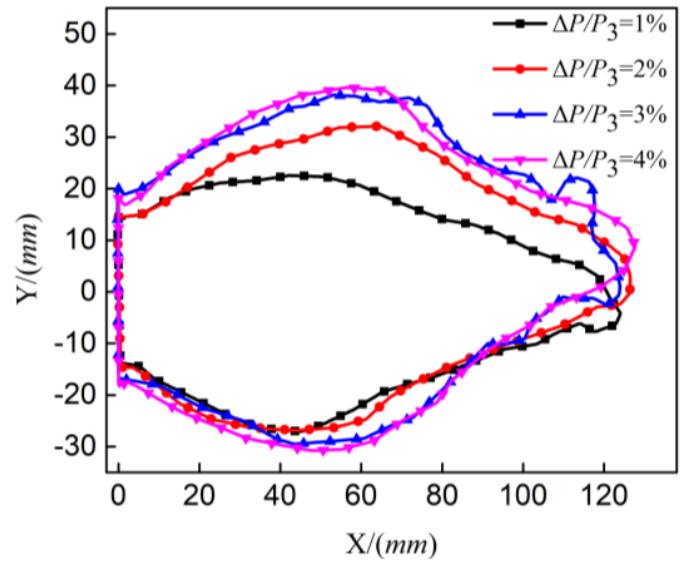

Figure 12. Comparison of the recirculation zones of Plane 1 under different pressure drops

Figure 10 shows the spray characteristics of Plane 1 under different pressure drops when the fuel-air ratio is 0.02 . Figure 11 and Figure 12 show flow field characteristics of Plane 1 under different pressure drops.

From Figure 10, It can be seen that the intensity of the fuel-LIF and the spray cone in Plane 1 become higher with the increase of pressure drops at the same fuel-air ratio. The results in Figure 11 and Figure 12 show that with the increase of swirler pressure drop, the jet velocity at the exit of the swirler, the jet expansion angle, and the width of the recirculation zone become higher. The reason for the above phenomenon is that the velocity of the airflow is proportional to the pressure drop.

As the pressure drop increases, the relative concentration of droplets in the center of the combustor decreases first and then increases. When the pressure drop is $1 \%$, the amount of fuel is small, which makes the primary atomization not good enough to fully open the spray cone, and a lot of droplets directly enter the main combustion zone following the swirl air. With the increase of pressure drop, the swirl intensity become higher and the fuel is injected from the pressureswirl atomizer at a higher speed, which makes the atomization performance better, and more and more fuel are drawn to the main combustion zone. It can also be seen that the width of spray cone becomes higher as the pressure drop increases. The higher jet velocity, the higher expansion angle and recirculation zone make the width of spray cone become higher.

\section{ONCLUSIONS}

In this paper, the spray characteristics of a double-swirl low-emission combustor are analysed by using PIV technology and PLIF technology in the optical three-sector combustor test rig, the interaction between sectors and the influence of venturi angle on spray structure are explained. The results show:

(1) The flow field plays a decisive role in the forming of spray structure. The spray cone is mainly formed by the high-speed jet as the droplets are following the swirl air, and the recirculation zone has a great influence on the fuel distribution in the central area. 
(2) The fuel concentration in the central area of Plane 5 is higher than that of Plane 1, and there is no hollow spray cone in Plane 5, especially when the venturi angle is $52^{\circ}$, $90^{\circ}$. The main reason is that the width of the recirculation zone, the jet velocity and the jet expansion angle in Plane 5 are higher than those in Plane 1.

(3) The venturi angle has a great influence on the flow spray structure. The fuel concentration at upstream of Plane 1 becomes higher with the increase of venturi angle.

(4) The intensity of the fuel-LIF and the spray cone in Plane 1 become higher with the increase of pressure drops. The higher jet velocity, the higher expansion angle and recirculation zone make the width of spray cone (h) become higher.

\section{NOMENCLATURE}

PIV Particle Imaging Velocimetry

$\triangle \mathrm{P} \quad$ Pressure Difference

P3 Pressure at the Swirler Inlet

$\triangle \mathrm{P} / \mathrm{P} 3 \quad$ Pressure Drop

PLIF Planar Laser Induced Fluorescence

LBO Lean Burnout

$\triangle \mathrm{P} \quad$ Pressure Difference

P3 Pressure at the Swirler Inlet

$\triangle \mathrm{P} / \mathrm{P} 3 \quad$ Pressure Drop

SMD Sauter Mean Diameter

\section{ACKNOWLEDGMENTS}

This work was supported by the Project 91641109 and the Project 51306182 of National Natural Science Foundation of China.

\section{References}

[1] LEFEBVRE A H, BALLAL D R. Gas turbine combustion : alternative fuels and emissions [J]. Journal of Engineering for Gas Turbines \& Power, 2010, 132(11): 77.

[2] DEREKDUNN-RANKIN. Lean combustion : technology and control [M]. Academic Press, 2013.

[3] AIAA. Swirl cup modeling - Part VIII: Spray combustion in CFM-56 single cup flame tube [J]. Aiaa Journal, 2003,

[4] WANG H, MCDONELL V, SAMUELSEN S. Influence of hardware design on the flow field structures and the patterns of droplet dispersion: part I - mean quantities [J]. Journal of Engineering for Gas Turbines \& Power, 1995, 117(117): 282-9.

[5] ATESHKADI A, MCDONELL V, SAMUELSEN G. Effect of mixer geometry on fuel spray distribution, emissions and stability; proceedings of the Aiaa Aerospace Sciences Meeting and Exhibit, F, 2013 [C].

[6] WANG H, MCDONELL V, SOWA W A, et al. Scaling of the Two-Phase Flow Downstream of a Gas Turbine Combustor Swirl Cup:Part I\&mdash;Mean Quantities [J]. Journal of Engineering for Gas Turbines \& Power, 1992, 115(3): V003T06A31.

[7] WANG H, MCDONELL V, SAMUELSEN G. The influence of spray angle on the continuous- and discrete-phase flowfield downstream of an engine combustor swirl cup [J]. Aiaa Journal, 2013,

[8] ATESHKADI A, MCDONELL V, SAMUELSEN G S. Lean blowout model for a spray-fired swirl-stabilized combustor [J]. Proceedings of the Combustion Institute, 2000, 28(1): 1281-8.

[9] MONGIA H, GORE J, GRINSTEIN F, et al. Combustion research needs for helping development of next-generation advanced combustors [J]. 2013,
[10] HADEF R, LENZE B. Effects of co- and counter-swirl on the droplet characteristics in a spray flame [J]. Chemical Engineering \& Processing Process Intensification, 2008, 47(12): 2209-17.

[11] LI G, GUTMARK E J. Combustion characteristics of a multiple swirl spray combustor [J]. 2003,

[12] SEOL W S, HAN Y M, LEE D S. Flow and Spray Characteristics of a Lean Fuel Injection Module With Radial Swirlers; proceedings of the ASME Turbo Expo 2000: Power for Land, Sea, and Air, F, 2000 [C].

[13] LILLEY D G. Swirl Flows in Combustion: A Review [J]. Aiaa Journal, 2011, 15(15): 1063-78.

[14] ELKADY A M. Experimental investigation of aerodynamics, combustion, and emissions characteristics within the primary zone of a gas turbine combustor [J]. 2006,

[15] LI G. Emissions, combustion dynamics, and control of a multiple swirl combustor [J]. Emissions, 2004,

[16] CAI J. Aerodynamics of lean direct injection combustor with multi-swirler arrays [J]. Dissertation Abstracts International, Volume: 67-04, Section: B, page: 2095;Adviser: San-Mou Jeng, 2006,

[17] YUAN Yi-Xiang, LIN Yu-Zhen, LIU Gao-En. Effects of flow field and spray on the lean and oil-extinguishing of the head of a swirling cup combustion chamber[J]. Journal of Aerospace Power, 2004, 19(3): 332-7.

[18] YUAN Yi-Xiang, LIN Yu-Zhen, LIU Gao-En. Study on Widening Combustion Stabilization Working Range of ThreeCyclone Head Combustion Chamber[J]. Journal of Aerospace Power, 2004, 19(1): 142-7.

[19] Liu Wei, Lin Yuzhen, Liu Gaoen, et al. Study on Combustion Efficiency of Composite Multistage Swirl Cup Combustor under Low Pressure[J]. Journal of Aerospace Power, 2004, 19(5): 650-5

[20] Zhang Chi, Zhang Rongwei, Xu Guoqiang, et al. Atomization effect of direct-type double-swirl air atomizing nozzle[J]. Journal of Aerospace Power, 2006, 21(5): 805-9.

[21] LIU C, LIU F, YANG J, et al. Experimental Investigation of Spray and Combustion Performances of a Fuel-staged Low Emission Combustor Part I: Effects of Main Swirl Angle; proceedings of the ASME Turbo Expo 2016: Turbomachinery Technical Conference and Exposition, F, 2016 [C].

[22] BOEHM B, DREIZLER A, GNIRSS M, et al. Experimental Investigation of Turbulence Structure in a Three-Nozzle Combustor; proceedings of the ASME Turbo Expo 2007: Power for Land, Sea, and Air, F, 2007 [C]. 